\title{
Non-Neoplastic Testicular and Paratesticular Lesions - Study from A Remote Indian Island
}

\author{
Chitrawati Bal Gargade and Archana Hemant Deshpande* \\ Department of Pathology, Andaman \& Nicobar Islands Institute of Medical Sciences, Port Blair, \\ Andaman \& Nicobar Island, India, PIN - 744101
}

\begin{abstract}
Background: Testicular and paratesticular lesions can represent a wide range of medical issues, from benign congenital conditions to life threatening malignancies and acute surgical emergencies. Most of the studies are done about the testicular tumors and very little literature is available about non-neoplastic lesions of testis and paratesticular tissue. Hence present study was undertaken to know the histomorphologic spectrum of nonneoplastic testicular and paratestesticuar lesions.

Methods: This is a prospective study done over a three year period from Jan 2016 to Jan 2019 includes orchidectomy specimens and paratesticular tissue received for histopathological examination in the Department of Pathology of a newly established medical college on a remote Indian Island.

Result: Total 51 orchidectomy specimens and two paratesticular tissues are received for histopathological examination. Out of 51 orchidectomy specimens; non neoplastic testicular lesions (94.1\%) were far more common than neoplastic lesions (5.9\%). The most common non-neoplastic testicular lesion was torsion testis $(19 / 48=39.6 \%)$ and most cases were seen in first two decades. The youngest patient was 11 months and oldest was 42 years of age. Long standing hydrocele, Pyocele and haematocele were the second most common cause for orchidectomy, in forty plus age group. Undescended testis as cause comprised $7.6 \%$ of the total orchidectomy specimens. One case of Epididymal cyst was found. Two paratesticular tissues received. One specimen showed appendix of testis and was cause of recurrent epididymo- orchitis in 11 yrs old boy. Gubernaculum was found in another specimen in a case of vanishing testis syndrome. Neoplasms formed a miniscule proportion - only three cases were diagnosed.

Conclusion: Nonneoplastic lesions are more common than neoplastic lesions. Torsion testis was the commonest indication for orchidectomy in younger age group while hydrocele, pyocele and chronic haematocele were the common causes in older patients. Appendixes of testis, gubernaculum of vanishing testis, epididymal cyst as non-neoplastic paratesticular lesions found in few cases.
\end{abstract}

Keywords: Non Neoplastic; Torsion Testis; Microlithiasis; Paratesticular Lesions; Appendix of Testis.

\section{Introduction}

Testis can be involved by various pathologies and affect a wide age range. In young patients, the common indications for orchidectomy are predominantly non-neoplastic lesions like cryptorchidism, epididymo-orchitis, and torsion of testis. In middle and older age, common indications are pyocele, chronic haematocele, uneducable or recurrent hernia, unsalvageable testicular trauma and Fournier's gangrene. Bilateral orchidectomy is done in carcinoma prostate to achieve hormone control. Although testicular cancer accounts for only $1 \%$ of all tumors in male, it is the most common malignancy in males between $15 \& 34$ years of age. ${ }^{[1]}$

Our study was undertaken to study Histopathological spectrum and age wise distribution of non-neoplastic lesions of testis and paratesticular tissue.

\section{Materials and Methods}

The present study was a prospective study conducted between Jan 2016 to Jan 2019.All the testicular and paratesticular specimens received in the Department of Pathology of a newly established medical college located on a remote Indian Island were included in the study. Age, clinical details and indications of surgery/biopsy were noted from the requisition forms. Each specimen was subjected to detailed gross examination and the histopathological examination done on hematoxylin and eosin stained slides of all the specimens. Ziehl-Neelsen (ZN) staining for detection of acid fast bacilli (AFB) and immunohistochemistry (IHC) was done in neoplastic lesions wherever necessary.

\section{Result}

We studied 53 specimens comprising of 51 orchidectomy specimens and two paratesticular specimens. Out of the total 51 orchidectomy specimens, 94.1\% (48/51) were non-neoplastic lesions and 5.9\% (3/51) were diagnosed as neoplastic lesions. (Fig.1) Table 1 shows age wise distribution of various non - neoplastic and neoplastic lesions of testis and paratesticular lesions. 
The most common (19/48=39.6 \%) non-neoplastic pathology in orchidectomy specimen was testicular torsion (Fig 2). Torsion testis was commonly found in second and third decade of life (Fig 3). The youngest patient was 11 month and oldest was 42 years of age. Grossly torsion testis (TT) specimen showed dusky, purple coloured testicular capsule and hemorrhagic parenchyma . Histological findings were determined based on time of onset of torsion and surgery. Most of the lesions were grade $3(12 / 19=63.1 \%)$ showing extensive areas of infarct and haemorrhage without any viable seminiferous tubules. Four out of 19 cases (21\%) showed grade 2 lesion comprising of haemorrhage infarction and few viable seminiferous tubules. In only 3 out of 19 cases (15.8\%) grade 1 lesions seen where of Interstitial edema and loss of epithelium in few seminiferous tubules were observed. Grade I torsion testis in 17 yrs old boy also showed microlithiasis (Fig 4) in the form lamellated calcifications in seminiferous tubules.

Next in frequency was a group of lesions composed of long-standing hydrocele, Haematocele and Pyocele $(12 / 48=25 \%)$. Pyocele was seen in 5 specimens; four specimens showed chronic Haematocele while hydrocele was seen in three cases. Haematocele on ultrasonography and clinically mimicked testicular neoplasm. Haematocele on gross examination showed a thick capsule with brownish black clotted blood and focal calcification and atrophic testis. (Fig 5) Microscopy of haematocele showed thickened fibrous capsule, large areas of haemorrhage, amorphous debris material, cholesterol clefts, abundant haemosiderin laden macrophages and atrophic testicular parenchyma.

Hydrocele was seen in older than 40 yrs of age except in 20 yrs male. Extensive exploration in this case of bilateral hydrocele didn't reveal any filaria.

Acute epididymo-orchitis is the third common nonneoplastic lesions $(5 / 48=10.4 \%)$, seen in patients with age ranged from 15-68 years .Tuberculous epididymo-orchitis was seen in 28 yrs old male contributing $2.1 \%$ of nonneoplastic lesions. Patient presented with scrotal swelling with multiple sinuses. Sections from epididymis, testis and scrotal skins revealed epitheloid granulomas composed of caseous necrosis, epitheloid cells, multinucleated Langhan's giant cells, fibroblasts and lymphocytes. ZN stain in the sections showed acid fast bacilli.

Cryptorchidism was the reason for orchidectomy in four (8.3\%). Cryptorchidism was mostly seen in second decade. Histopathologically three out of four cryptochid testis showed maturation arrest at different levels. Cryptochid testis of 68 yrs male showed features of atrophy. Intratubular germ cell neoplasm was not seen in any specimen of cryptochid testis.

Orchidectomy was done for Fournier's gangrene in 3 cases $(6.3 \%)$. All three patients had uncontrolled diabetes. Epididymal cyst was an incidental finding in a left orchiectomy specimen removed for Fournier's gangrene $(2.0 \%)$.

A grey white soft tissue measuring $1 \times 0.5 \times 0.4 \mathrm{~cm}$ with attached cord measuring $3.5 \mathrm{~cm}$ was received from $11 \mathrm{yrs}$ male as Gubernaculum in a case of left vanishing testis. Microscopically it showed fibrocollagenous tissue, dilated and congested vessels, mild chronic inflammatory cell infiltrate. Section from spermatic cord showed normal Vas Deferens on histopathological examination.

A flattened white tissue piece measuring $1 \times 0.3 \times 0.1 \mathrm{~cm}$. was received from a case of recurrent eppididymoirchitis of $14 \mathrm{yrs}$ male as torsion of appendix. Microscopy showed fibrovascular tissue lined by columnar epithelium (Fig 6) and dense acute inflammatory infiltrate in subepithelium

Out of 51 orchidectomy specimens, three $(5.8 \%)$ showed neoplasm. One benign lesion was adenomatoid tumor arising from tunica of testis while other two were malignant lesions. Both malignant testicular tumors were germ cell tumors; seminoma was seen in 58 yrs old patient and yolk sac tumor in 28 yrs old adult.

Table 1: Age wise histopathological spectrum of testicular and paratesticular lesions.

\begin{tabular}{|c|c|c|c|c|c|c|c|c|c|c|}
\hline \multirow{2}{*}{$\begin{array}{l}\text { Histopathological } \\
\text { Diagnosis }\end{array}$} & \multicolumn{9}{|c|}{ Age in years } & \multirow{2}{*}{ Total } \\
\hline & $0-10$ & $11-20$ & $21-30$ & $31-40$ & $41-50$ & $51-60$ & $61-70$ & $71-80$ & $81-90$ & \\
\hline \multicolumn{10}{|c|}{ TESTICULAR LESIONS - NON NEOPLASTIC } & 48 \\
\hline Torsion Testis & 3 & 7 & 6 & 2 & 1 & - & - & - & - & 19 \\
\hline Undescended Testis & - & 2 & 1 & - & - & - & 1 & - & - & 4 \\
\hline Fournier gangrene & - & - & 1 & - & - & - & 2 & - & - & 3 \\
\hline Acute Epididymoorchitis & - & 1 & 2 & - & - & 1 & 1 & - & - & 5 \\
\hline $\begin{array}{l}\text { Tuberculous } \\
\text { Epididymorchitis }\end{array}$ & - & - & 1 & - & - & - & - & - & - & 1 \\
\hline Hernia & - & - & - & - & - & - & 1 & 1 & - & 2 \\
\hline
\end{tabular}




\begin{tabular}{|c|c|c|c|c|c|c|c|c|c|c|}
\hline \multirow{2}{*}{$\begin{array}{l}\text { Histopathological } \\
\text { Diagnosis }\end{array}$} & \multicolumn{9}{|c|}{ Age in years } & \multirow{2}{*}{ Total } \\
\hline & $0-10$ & $11-20$ & $21-30$ & $31-40$ & $41-50$ & $51-60$ & $61-70$ & $71-80$ & $81-90$ & \\
\hline Hydrocele & - & 1 & - & - & - & 1 & - & 1 & - & 3 \\
\hline Pyocele & - & - & - & - & 2 & 1 & 2 & - & - & 5 \\
\hline Haematocele & - & - & - & - & 2 & - & - & - & 2 & 4 \\
\hline Epididymal Cyst & - & - & - & - & - & - & 1 & - & - & 1 \\
\hline Therapeutic Orchidectomy & - & - & - & - & - & - & - & 1 & - & 1 \\
\hline \multicolumn{10}{|c|}{ TESTICULAR LESIONS - NEOPLASTIC } & 3 \\
\hline \multicolumn{10}{|c|}{ Benign } & 1 \\
\hline Adenomatoid tumor & - & - & - & - & - & 1 & - & - & - & \\
\hline \multicolumn{10}{|c|}{ Malignant } & 2 \\
\hline Seminoma & - & - & - & - & - & 1 & - & - & - & \\
\hline Yolk sac Tumor & - & - & 1 & - & - & - & - & - & - & \\
\hline \multicolumn{10}{|c|}{ PARATESTICULAR LESIONS - NON NEOPLASTIC } & 2 \\
\hline Gubernaculum & - & 1 & - & - & - & - & - & - & - & 1 \\
\hline Appendix of Testis- & - & 1 & - & - & - & - & - & - & - & 1 \\
\hline \multicolumn{10}{|c|}{ PARATESTICULAR LESIONS - NEOPLASTIC } & 0 \\
\hline
\end{tabular}

Table 2: Comparison of frequency of benign and malignant lesions.

\begin{tabular}{|c|c|c|}
\hline Author & $\begin{array}{c}\text { Non - neoplastic } \\
\text { lesions }\end{array}$ & $\begin{array}{l}\text { Neoplastic } \\
\text { lesions }\end{array}$ \\
\hline T.Sundari et al ${ }^{[2]}(2015)$ & $94.2 \%$ & $5.8 \%$ \\
\hline Deore K.S et al ${ }^{[3]}(2015)$ & $91.7 \%$ & $8.2 \%$ \\
\hline Sharma M. et al ${ }^{[4]}(2017)$ & $93 \%$ & $7 \%$ \\
\hline Charak et al ${ }^{[5]}(2018)$ & $90.1 \%$ & 9.8 \\
\hline Present study & $94.1 \%$ & $5.1 \%$ \\
\hline
\end{tabular}

Table 3: Incidence of epididymo-orchitis in various studies.

\begin{tabular}{|l|c|c|c|c|c|}
\hline Lesion Author & $\begin{array}{c}\text { Patel MB } \\
\text { (2015) }\end{array}$ & $\begin{array}{c}\text { Reddy H } \\
\text { (2016) }\end{array}$ & $\begin{array}{c}\text { Abba K } \\
\text { (2016) }\end{array}$ & $\begin{array}{c}\text { M.Sharma } \\
{ }^{[4]}\end{array}$ & Present study $^{\text {(2017) }}$ \\
\hline Acute epididymoorchitis & $16.47 \%$ & $19.76 \%$ & $4.3 \%$ & $5.66 \%$ & $10.4 \%$ \\
\hline Tubercular epididymo-orchitis & $9.4 \%$ & $3.5 \%$ & $12.9 \%$ & $3.77 \%$ & $2.1 \%$ \\
\hline
\end{tabular}

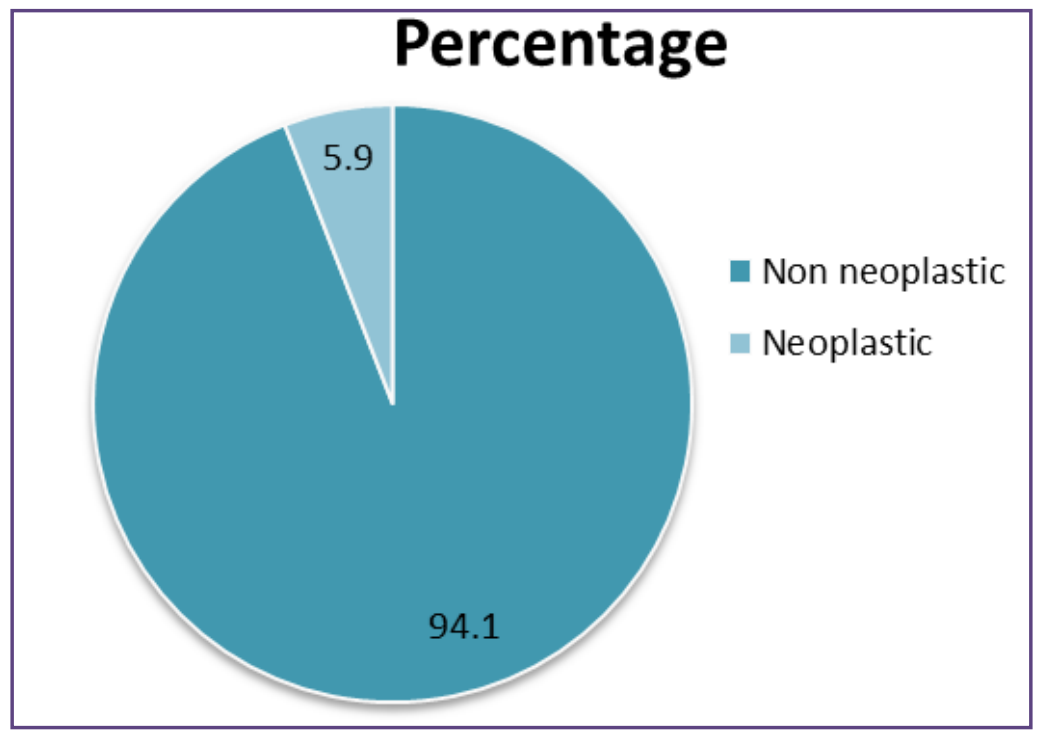

Fig. 1: Graph showing frequency of neoplastic and non-neoplastic testicular and paratesticular lesions. 


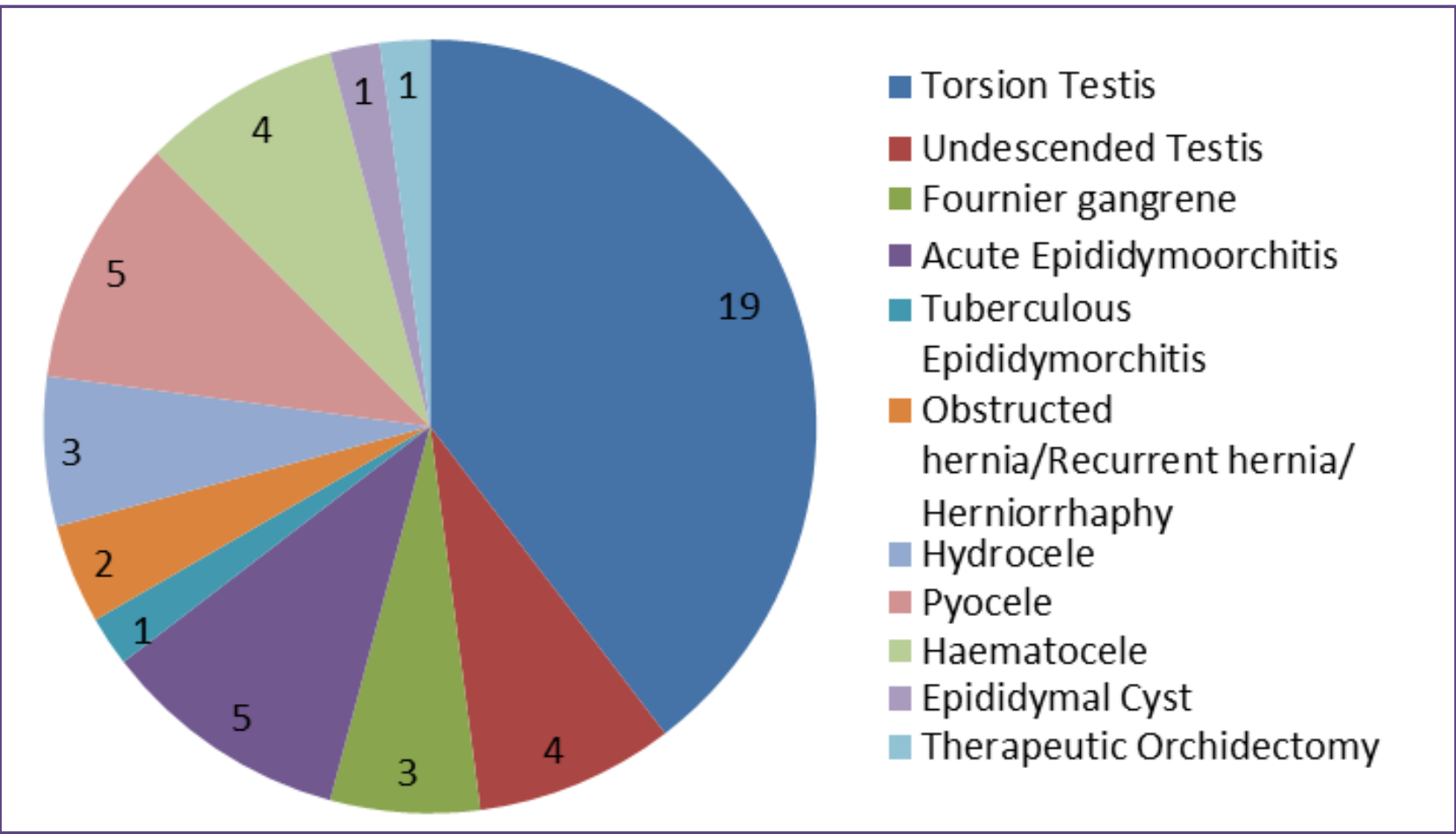

Fig. 2: Histopathological spectrum of non - neoplastic lesions of testis.

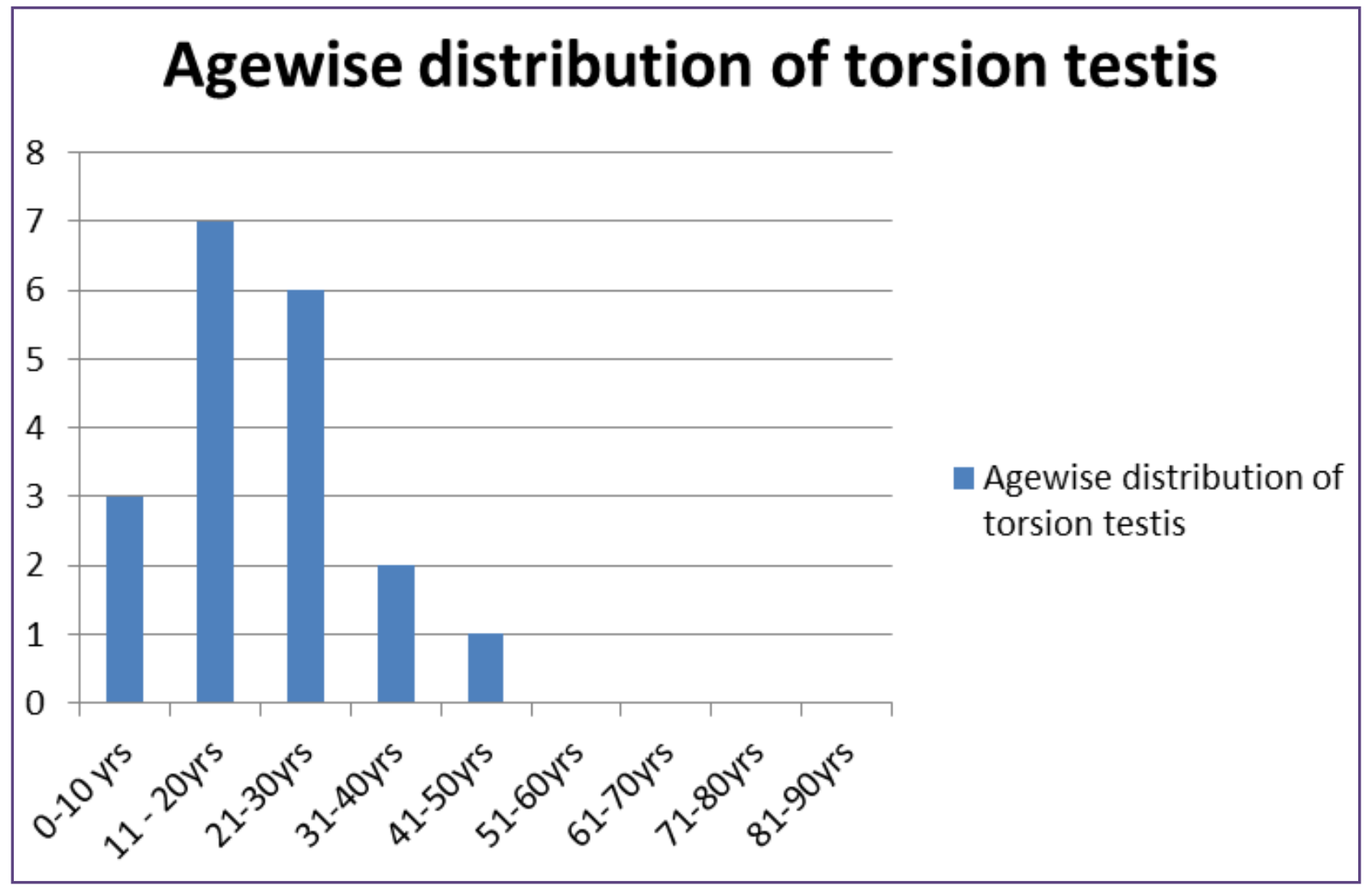

Fig. 3: Graph showing age wise distribution of torsion testis. 


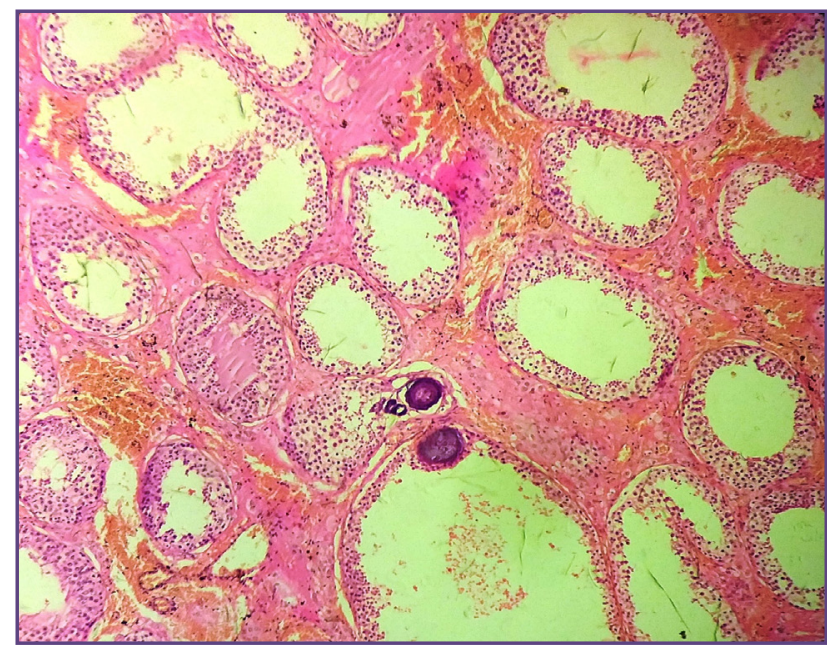

Fig. 4: Grade I infarction of testis with microlithiasis (H\&E 100X).

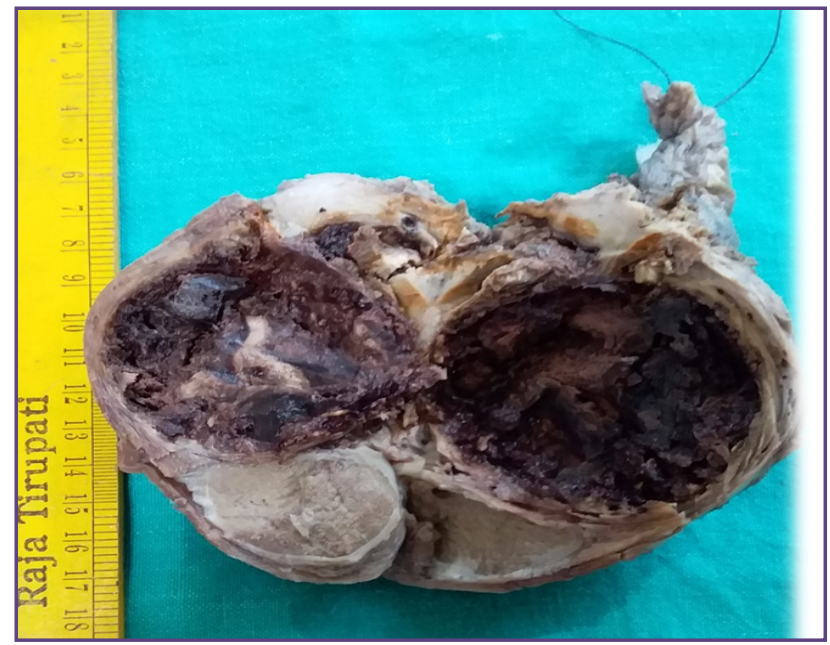

Fig. 5: Gross specimen of Haematocele showing blood filled cavity, compressed testis and thickened wall.

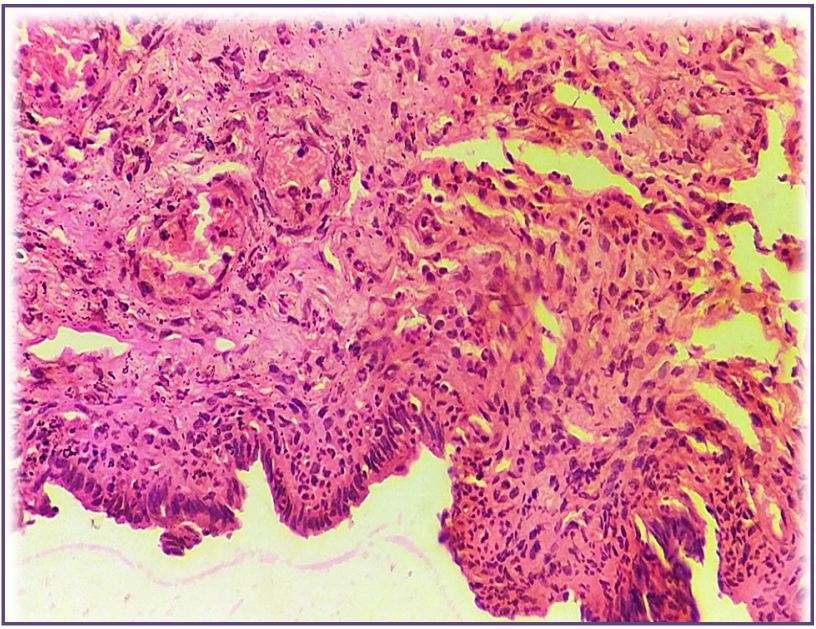

Fig. 6 : Appendix of testis lined by columnar epithelium . ( H\&E 100X).

\section{Discussion}

The present study dealt with tumor and tumor like lesions of testis and paratesticular structures. In our study only 3 out of 51 orchidectomy specimens showed neoplastic pathology comprising $5.1 \%$. While non-neoplastic lesions were more common constituting $94.1 \%$. This pattern was correlating with other studies as shown in Table 2.

Torsion testis: The most commonly found non-neoplastic lesion was torsion and infarction constituted $39.6 \%$ in the present study. Torsion testis was also the commonest non-neoplastic pathology in other studies. ${ }^{[6,7]}$ Time is the most critical factor in the emergency care of torsion testis .The success of surgery within 4-8 h from the onset of the symptoms is around $90 \%-100 \%$, but after 12 hours it is $50 \%$ and after 1 day only $10 \%{ }^{[8]}$ Delay can be fatal and may lead to impaired fertility and loss of the testicles. Depending upon the interval between the onset of torsion and surgery, Mikuz ${ }^{[9]}$ has graded morphological changes in torsion testis. Typical ischemia of Grade 1 is dominated by marked edema and some loss of seminiferous epithelium and occurs during first four hours of torsion. The grade 2 injuries are characterized by a diffuse interstitial haemorrhage and tubular necrosis which is seen between 4 to 6 hours. The grade 3 injury is fully developed haemorrhagic infarction of the testis and is seen after 12 hours or more.

In our study most of the lesions (63.1\%) showed grade 3 morphology. Unfortunately, many patients presented late and orchiectomy was the only final option left in the management of torsion testis like in other studies. ${ }^{[10]}$

Two peaks were seen in torsion testis; perinatal and in pubertal life but few cases were also seen in adults or elderly patients. ${ }^{[11]}$ In our study and other studies, ${ }^{[4.7]}$ torsion testis was commonly noted in second decade of life. Two cases of torsion testis were seen in our study, one in $4^{\text {th }}$ decade and other in $5^{\text {th }}$ decade.

Microlithiasis of testis was noted in torsion testis of 17 yrs old boy where laminated calcification was seen in seminiferous tubules. Rest of the testis showed features of grade 1 torsion testis. Extensive search did not reveal any intratubular germ cell neoplasia or frank malignancy. Two types of testicular microliths have been described as haematoxylin bodies and lamellated calcifications. [12] Uninvolved seminiferous tubules by microlithiasis often show abnormal spermatogonia and reduced luminal diameters. Testicular microlithiasis is an uncommon condition characterized by calcifications within the seminiferous tubules and is associated with many 
conditions like cryptorchidism, spermatic cord torsion, infertility, hypogonadism ${ }^{[13]}$ and testicular malignancy. ${ }^{[14]}$ Many authors recommend regular ultrasound follow-up, tumour marker determination and physical examination for early detection of malignancy where microlithiasis was noted. ${ }^{[15]}$

Orchidectomy in Pyocele or Hydrocele Or Haematocele: In this study 12 out of 48 specimens $(25 \%)$ revealed long standing hydrocele, Haematocele and Pyocele. Pyocele was seen in 5/48(10.4\%), hydrocele in 3/48 and Haematocele in $4 / 48$ non neoplastic lesions. All these Pyocele were seen in middle aged patients. i.e. after $40 \mathrm{yrs}$ age. Such high incidence of pyocele 10/77 (12.9\%) and 20/112 (17.8\%) was also observed in other studies. ${ }^{[16,5]}$

Chronic haematocele are rare scrotal masses. Possible most common caused include direct trauma of the scrotum, torsion, tumor and surgery. Large haematocele distort the adjacent testis, leading to increased suspicion of malignancy, both clinically and by ultrasound. Only 35 cases of chronic Haematocele reported so far in the known world literature, few scattered case reports published in medical journals of different languages with a maximum of two cases reported by some authors. ${ }^{[17]}$ In present study we had 4 cases of chronic Haematocele.

Undescended testis (cryptorchidism) and vanishing testis syndrome: In our study, undescended testis constitutes $8.3 \%$ of non-neoplastic testicular lesions which is similar to other study from Gujarat ${ }^{[7]}$ but incidence noted in our study is much less compared to other studies in India. ${ }^{[3,4]}$ The treatment of undescended testis should begin after six months and ideally be completed by the child's first birthday. In our study majority of the patients who presented were in the age group of 15-25 and above. In all cases testis was located in the inguinal region. In other studies also, ${ }^{[4,16]}$ patients presented late and orchidectomy was only the treatment option left than orchidopexy.

Cryptorchidism is the main risk factor for testicular cancer. However intra-tubular germ cell neoplasm was not seen in our study. Similar was reported by others. ${ }^{[2,18]}$ The nonpalpable testicle when associated with a blind-ending spermatic cord is called as "vanishing testis syndrome" or' 'testicular regression syndrome". It is characterized by partial or total absence of testicular tissue, unilateral or bilateral, with or without rudimentary epididymis and spermatic cord structure in 46XY individual with normal genitalia. The presence of spermatic cord structure is evidence of the presence of the testis in early intrauterine life. Testis regression syndrome (TRS) or vanishing testis syndrome was reported in less than 5\% of cryptorchidism cases; ${ }^{[19]}$ while some documented TRS in $35 \%$ to $60 \%$ of patients with cryptorchidism. ${ }^{[20]}$ In our study out of five cases of cryptorchidism; one showed features of TRS $(20 \%)$ histologically and clinically. It was consistent with study from India where 19 out of 56 cryptochid testes showed TRS $(25.3 \%){ }^{[21]}$

Fournier gangrene: Fournier gangrene was the reason for bilateral orchidectomy in three out of 48 cases. In management of Fournier's gangrene testis is usually preserved if it is viable. In our study most of patients presented late. During surgery it was found that bilateral testes were extensively involved and non-viable. Hence orchidectomy was performed.

Epididymo-orchitis: In acute pyogenic orchitis epididymis also gets affected commonly. The testis may show abscesses or may be fibrotic and adherent to the surrounding tissues, thus mimicking a neoplasm. In present study acute epididymoorchitis accounted 10.4\%while tuberculous epididymoorchitis was detected in one out of 48 cases $(2.1 \%)$. Table 3 presents variable incidence of acute and tubercular epididymoorchitis in various studies.

Epididymal cysts: Epididymal cysts are either true epididymal cysts lined by epithelium and contain clear serous fluid or they may be spermatoceles. They are important macroscopic mimickers of testicular and paratesticular neoplasia. In our study, we reported 1 case (2.1\%) of epididymal cyst. Khandeparkar et al ${ }^{[24]}$ reported 17 cases $(36.2 \%)$ while Gaikwad et al ${ }^{[25]}$ reported 15 cases $(14.8 \%)$ in their study.

Appendix Testis: Testicular and epididymal appendages were once considered anatomical anomalies; however, some studies report that these structures are present in the majority of normal individuals. When these structures are too long or pedunculated, they can twist around their own axis, causing acute scrotum mimicking testicular torsion. Approximately $80 \%$ of individuals have an appendix testis, with bilaterality in one-third of them. The appendix is covered by a cuboidal or columnar epithelium. The structure has a highly vascular fibrous core, the stroma shows variable numbers of smooth muscle cells and gland like structures. Due to pedunculated structure, the appendix testis can get twisted, causing hemorrhagic infarction and severe testicular pain. ${ }^{[26]}$ This event occurs most often in prepubertal or pubertal boys and may be related to the possible growth of the appendix as a result of stimulation by androgens and estrogens at this period of time. ${ }^{[27]}$ In our study torsion of the appendix testis was found in 14 years old boy and he recovered satisfactorily. Timely diagnosis and management prevented orchidectomy in this young boy. 


\section{Conclusion}

This study represents the various reasons for orchidectomy. Non-neoplastic lesions were more common than the neoplastic lesions of testis. Paratesticular tissue like appendix of testis are rarely received for histopathological examination as suspected cases of torsion of appendix of testis. They are usually treated with rest, observation, analgesics and scrotal support. Out of all non-neoplastic lesions, vascular lesions like torsion and infarction are the most common in young and adults. Histopathological changes depend upon the time lapsed and time of surgery and early recognition and management may prevent the inevitable loss of the testis.

\section{Acknowledgements}

None

\section{FUNDING}

No

\section{Competing Interests}

No conflict of Interest

\section{Reference}

1. Scott K. Testicular Cancer. American Family Physician 1999; 59 (9): 2539- 50

2. Devi TS, Nirmala BV, Srivani N, Kumar OS. Spectrum of orchidectomy lesions: 5 yrs study. Journal of Evidence based Medicine and Healthcare; 2015;26(2):3880-92.

3. Deore KS, Patel MB, Gohil RP, Delvadiya KN, Goswami HM. Histopathological analysis of testicular tumours: A 4-year experience. Int J Med Sci Public Health. 2015 Apr 1;4(4):554-7.

4. Sharma M, Mahajan V, Suri J, Kaul KK. Histopathological spectrum of testicular lesions-A retrospective study. Indian J Pathol Oncol. 2017;4(3):437-41.

5. Charak A, Ahmed I, Sahaf BR, Qadir R, Rather AR. Clinicopathological spectrum of testicular and paratesticular lesions: a retrospective study. International Journal of Research in Medical Sciences. 2018;6(9):3120-3.

6. Baidya R, Sigdel B, Baidya NL. Histopathological pattern of testicular lesion. Journal of Pathology of Nepal. 2017; 7(1):1087-90.

7. Patel MB, Goswami HM, Parikh UR, Mehta N. Histopathological study of testicular lesions. Gujrat Med J. 2015;70(1):41-6.

8. Sharp VJ, Kieran K, Arlen AM. Testicular torsion: diagnosis, evaluation, and management. Am Fam Physician 2013; 88(12):835-40.

9. Mikuz G. Testicular torsion: simple grading for histological evaluation of tissue damage. Applied pathology. 1985;3(3):134-9.
10. Davol P, Simmons J. Testicular torsion in a 68 year old man. Urology. 2005; 66(1):195-7.

11. Renshaw AA. Testicular calcifications: incidence, histology and proposed pathological criteria for testicular microlithiasis. The Journal of urology.1998;160(5):1625-8.

12. Ganem JP, Workman KR, Shaban SF. Testicular microlithiasis is associated with testicular pathology. Urology 1999;53(1):209-13.

13. Furness PD, Husmann DA, Brock JW, Steinhardt GF, Bukowski TP, Freedman AL, Silver RI, Cheng EY. Multiinstitutional study of testicular microlithiasis in childhood: a benign or premalignant condition? The Journal of urology. $1998 ; 160(2): 1151-4$.

14. Guzmán PM, Hita GV, Fernández TA, Miñana BL, Martínez FD, Sánchez FG. et al Significance and management of testicular microlithiasis. Archivos espanoles de urologia. $2003 ; 56(5): 472-7$.

15. Kappikeri VS, Thalasta P. Clinical study and analysis of orchidectomies done at Basaveshwara Teaching and General Hospital, Kalaburagi, Karnataka, India. International Surgery Journal. 2016 ;3(3):1460-4.

16. Babakri MM. Chronic scrotal hematocele: a rare entity and diagnostic dilemma. Urol Nephrol Open Access J. 2017;4(5):00142.

17. Koni A, Ozseker HS, Arpali E, Kilinc E, Dogan HS, Akyol A, Tekgul S. Histopathological evaluation of orchiectomy specimens in 51 late postpubertal men with unilateral cryptorchidism. The Journal of urology. 2014 1;192(4):1183-8.

18. Spires SE, Woolums CS, Pulito AR, Spires SM. Testicular regression syndrome: a clinical and pathologic study of 11 cases. Archives of pathology \& laboratory medicine. 2000 ;124(5):694-8.

19. Pirgon Ö, Dündar BN. Vanishing testes: a literature review. Journal of clinical research in pediatric endocrinology. 2012 ;4(3):116-20

20. Mathew M. Testicular regression syndrome: Useful diagnostic approach. IOSR Journal of Dental and Medical Sciences. 2018;17(1):07-10.

21. Reddy H, Chawda H, Dombale VD. Histomorphological analysis of testicular lesions. Indian Journal of Pathology and Oncology.2016;3(4);558-63

22. Abba K, Tahir MB, Dogo HM, Nggada HA. Testicular and Paratesticular Non-Neoplastic lesions in University of Maiduguri Teaching Hospital: A 10-year Retrospective Review. Bo Med J. 2016;13(1):39-44.

23. Khandeparkar SG, Pinto RG. Histopathological spectrum of tumor and tumor-like lesions of the paratestis in a Tertiary Care Hospital. Oman medical journal. 2015;30(6):461-8.

24. Gaikwad Sheela L, Patki Supriya P. Clinicopathological study of testicular and paratesticular lesions. International Journal of Contemporary Medical Research 2017;4(3):610-3 
25. Skoglund RW, Mcroberts JW, Ragde H. Torsion of testicular appendages: presentation of 43 new cases and a collective review. The Journal of urology. 1970 ;104(4):598-600.
26. Samnakay N, Cohen RJ, Orford J, King PA, Davies RJ. Androgen and oestrogen receptor status of the human appendix testis. Pediatric surgery international. 2003;19(7):520-4.

\section{*Corresponding author:}

Dr. Archana Hemant Deshpande, Professor \& Head of the Department, Department of Pathology, Andaman \& Nicobar Islands Institute of Medical Sciences, Port Blair, Andaman \& Nicobar Island, India, PIN - 744101

Phone: +919373127804

Email: ahdesh@gmail.com

Financial or other Competing Interests: None. 